\title{
Anhydrous ammonia pulmonary toxicity: A significant farming hazard
}

\author{
Irfan Waheed MD, Audra Fuller MD
}

\begin{abstract}
Anhydrous ammonia is a toxic gas widely used as a fertilizer. In 2016 about 12 million tons of ammonia were used in the production of fertilizers. We are reporting a case of severe pulmonary toxicity from anhydrous ammonia fertilizer exposure. An 80-year-old male farmer was accidentally exposed to anhydrous ammonia released from a pressurized fertilizer tank. He was intubated due to upper airway inhalation injury. Bronchoscopy showed extensive lower airway mucosal damage. The sloughed bronchial mucosa was removed from obstructed bronchi using a cryoprobe. He developed acute respiratory distress managed with lung protective mechanical ventilation. He did not improve and tracheostomy was recommended. The patient's family opted for comfort care only. Anhydrous ammonia can cause pulmonary toxicity. Symptoms range from mild to severe and can be fatal at doses greater than 5,000 parts per million. Early inspection of the upper respiratory tract and securing an airway are lifesaving. Management is supportive with oxygen and mechanical ventilation. Education, the use of protective gear, and proper equipment handling are key steps in the prevention of accidental toxicity.
\end{abstract}

Keywords: ammonia, toxic inhalation, acute respiratory failure, agriculture

\section{INTRODUCTION}

Ammonia is the third most abundantly produced toxic chemical in the world. Anhydrous ammonia is a pungent and toxic gas used extensively as a fertilizer in agriculture. In 201612 million tons of ammonia were used as fertilizer. ${ }^{1}$ Sixty percent of the total U.S. ammonia production capacity is centered in Louisiana, Oklahoma, and Texas. Anhydrous ammonia is stored and transported as a liquid in pressurized tanks. If it is released from the pressurized container, anhydrous ammonia will immediately return to a gaseous state and can cause respiratory toxicity.

The CDC reports ammonia to be the most common chemical involved in single agent toxic exposures. ${ }^{2}$

Corresponding author: Irfan Waheed

Contact Information: Irfan.waheed@ttuhsc.eduu

DOI: 10.12746/swrccc.v5i19.385
The 2014 Annual Report of the American Association of Poison Control Centers' National Poison Data System reported 2,083 single exposures to ammonia. ${ }^{3}$ Ammonia has the potential to cause a variety of toxicological mass events, e.g., industrial and transportation accidents. On April 17, 2013, a fire and an ammonium nitrate explosion at the West Fertilizer Company in West, Texas, resulted in 15 fatalities and 260 injuries. ${ }^{4}$ Accidental ammonia exposure and its potential for a toxicological mass events are usually unpredictable and adequate preparedness is of utmost importance. Part of such preparedness is conveying information to clinicians, which is the objective of this case report.

\section{CASE}

An 80-year-old male farmer was accidently exposed to anhydrous ammonia released from an ammonia fertilizer tank. The patient was driving a 


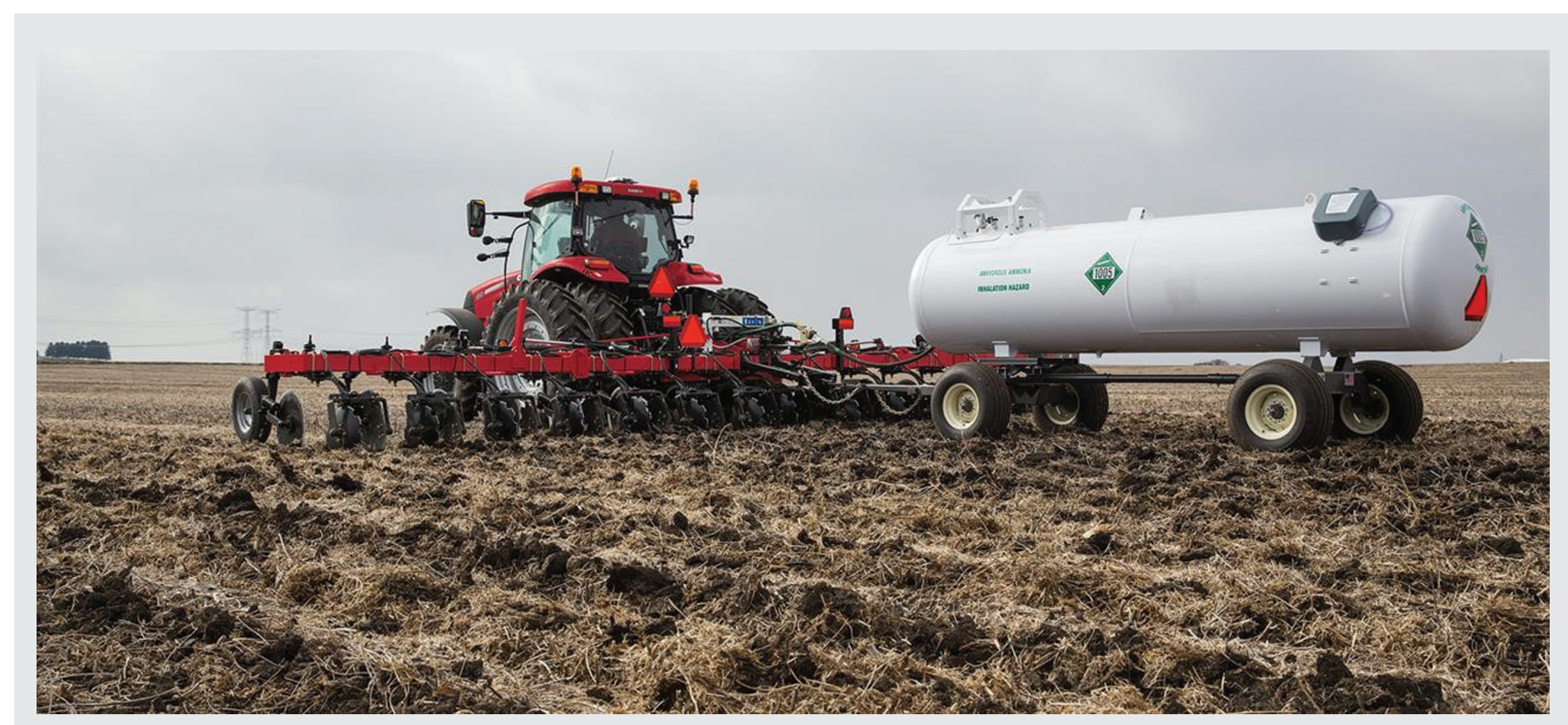

Figure Courtesy by: http://blog.caseih.com/equipment-technology/upgrade-your-fall-fertilizer-applications

tractor and fertilizing the fields with ammonia (Figure). A pipeline from the ammonia tank was broken, and gas filled the cab of the tractor. He was not wearing any protective gear. He was moved to a local hospital emergency department after an estimated 15-20 minutes of exposure to anhydrous ammonia.

On arrival, he was confused with a pulse rate 124 beats per minute, temperature $95.5{ }^{\circ} \mathrm{F}$, respiratory rate 24 breaths per minute, and blood pressure $170 / 102 \mathrm{mmHg}$. His tongue was edematous, and his lips, nasal mucosa, and oral mucosa were erythematous. $\mathrm{He}$ was in acute respiratory distress and auscultation of the lungs demonstrated expiratory wheezing. Endotracheal intubation was performed. The patient was then transferred to the Medical Intensive Care Unit at University Medical Center in Lubbock, TX. His initial management included mechanical ventilation, intravenous fluids, and pulmonary care. He was treated with corticosteroids and empiric antibiotics. He had intermittent fever, leukocytosis, and copious tracheal secretions.

His respiratory status deteriorated progressively despite protective lung ventilation measures. Due to unremitting hypoxemia and refractory alveolar edema, the patient underwent bronchoscopy. Initial bronchoscopic examination revealed diffuse erythematous tracheobronchial mucosa, petechiae, extensive bronchial mucosal sloughing, and obstruction of the subsegmental bronchi. The sloughed mucosa was removed from obstructed bronchi using a therapeutic bronchoscope with a cryoprobe. Post procedure, his oxygenation improved, and his positive end expiratory pressure was reduced.

On day twelve of admission, he was extubated. Shortly after extubation, he developed respiratory distress and required subsequent re-intubation. Tracheostomy was recommended, but his family decided on comfort measures. Subsequently, he was terminally extubated.

\section{Discussion}

Under atmospheric pressure, anhydrous ammonia is a colorless gas. For use as an agricultural fertilizer, it is compressed into a liquid state. Exposure 
to anhydrous ammonia can cause injury by two distinct mechanisms. First, an extremely low temperature $\left(-33^{\circ} \mathrm{C}\right)$ exerts its destructive effect by freezing tissues. Second, vaporization of ammonia is toxic to skin, eyes, and respiratory mucosa by the formation of hydroxyl ions $(\mathrm{OH})$ which cause chemical burns by liquefactive necrosis. ${ }^{5}$ The severity of an injury is directly related to the concentration and duration of ammonia exposure. Ammonia concentrations $>50 \mathrm{mg} / \mathrm{m}^{3}$ cause mild injury to the upper respiratory tract, and concentrations $>1000 \mathrm{mg} / \mathrm{m}^{3}$ can lead to severe respiratory distress. ${ }^{6}$ The low lethal concentration of anhydrous ammonia for humans is 5,000 parts per million (ppm) for a period of 5 minutes. ${ }^{7}$

Inhalation is the most frequent mode of exposure to anhydrous ammonia. The acute effects from inhalation range from mild to severe clinical presentations. Mild symptoms include nasal and throat irritation causing cough. Moderate injury causes edema and erythema of the lips and respiratory mucosal surfaces. Clinical findings in cases with moderate exposures include pharyngitis, laryngitis, productive cough, and bronchospasm. Patients may have rapid, shallow breathing, rhonchi, and blood tinged sputum. Severe effects include second and third-degree burns to the mucosa of the nasal passages, soft palate, larynx, and respiratory mucosa. Airway obstruction, severe bronchospasm, and copious sputum production can occur. Both epithelial and endothelial damage develop in alveolar injury resulting in an alveolar capillary leak and the pathologic changes of adult respiratory distress syndrome (ARDS). Severe damage to alveoli from inhalation injury is referred to as diffuse alveolar damage (DAD). ${ }^{8}$ Delayed effects of acute exposure of ammonia include bronchiectasis, bronchitis, reactive airway disease, dyspnea upon exertion, and chronic productive cough. Other chronic findings may include bronchiolitis, chronic obstructive pulmonary disease, and chronic respiratory failure. ${ }^{9}$

Immediately after the exposure, decontamination of skin and ocular mucosa should be a priority. This should include flushing of exposed areas with water for fifteen minutes. ${ }^{10}$ Nurse tanks are equipped with a water supply for first aid. There is no specific antidote for ammonia. Inspection of the upper airways is important because the mucosal membranes may be edematous. Anhydrous ammonia vapor in very high concentrations for short periods of exposure primarily affects the upper airway, causing bronchoconstriction and mucosal edema leading to rapid airway obstruction. It can be fatal if it causes immediate airway obstruction, but this may prevent further inhalation of the gas deeper into the lungs. In this setting, early intubation is life-saving. Because the lower airway is usually spared, extensive sloughing of the lower respiratory mucosa is unlikely. ${ }^{11}$

By contrast, patients who inhaled nonfatal ammonia concentrations for a longer duration will have more diffuse injury throughout the tracheobronchial tree because of increased depth of inhalation. ${ }^{12}$ Fiberoptic bronchoscopy is helpful for assessment of the inhalational injury as it can reveal erythema, congestion, hemorrhage, and extensive desquamation of the tracheobronchial tree. ${ }^{13}$ During the early phase of injury, hypoxemia and acute airway obstruction caused by the sloughing of mucosa pose the greatest threat. When endotracheal intubation is required, the largest possible diameter endotracheal tube should be used because mucosal sloughing may quickly occlude small diameter tubes. To facilitate the removal of secretions, early tracheostomy should be considered. Inhaled corticosteroids have not been shown to decrease mortality from ammonia injury and may increase morbidity. ${ }^{14}$

Following the early phase after injury, there is a gradual onset of airway obstruction which leads to irreversible pulmonary failure. Depending on the severity of exposure, this phase begins in the 48 to 72 hours post exposure. ${ }^{15}$ Fibrous obliteration of small airways combined with bronchiectasis can cause severe hypercarbia from an increase in dead space ventilation. ${ }^{14}$ Survivors may have a small, reversible component of bronchoconstriction related to the hyperactive airways. ${ }^{16}$ In most of the cases, chronic obstruction is fixed and poorly responsive to bronchodilators. The long term pulmonary prognosis of patients liberated from mechanical ventilation depends on the amount of fixed parenchymal scar. Pathological findings include fibrous obliteration of small airways consistent with late stage bronchiolitis obliterans which results in the obstructive component of this disease. ${ }^{13}$ 
Ventilated patients who cannot be weaned because of persistent respiratory failure will have increased mortality due to pneumonia despite maximal supportive care. ${ }^{17}$ Autopsy findings of ammonia inhalation injury reveal tracheobronchial ulcerations, denuded epithelium with pseudomembrane formation, diffuse alveolar damage, pulmonary edema, and bronchopneumonia. ${ }^{18}$

Simple protection from exposures can prevent serious consequences. To minimize the chance of an accident, workers should take steps to ensure all equipment is in proper working condition. All agricultural and industrial workers handling ammonia should have training in equipment maintenance, operation, use proper personal protective equipment, and access to emergency first aid. ${ }^{19}$

In summary, the management of anhydrous ammonia exposures requires early inspection of the upper airways. Supportive care with supplemental oxygen, bronchodilators, and mechanical ventilation is the mainstay of treatment. Prophylactic antibiotics are not recommended due to increasing the risk of infection with resistant organisms. When intubation is required, use the largest possible diameter endotracheal tube to allow adequate bronchial suctioning. Bronchoscopy and cryoprobes can help with the removal of sloughed tissue.

Article citation: Waheed I, Fuller A. Anhydrous ammonia pulmonary toxicity: a significant farming hazard. The Southwest Respiratory and Critical Care chronicles 2017; 5(19): 35-38

From: The Department of Internal medicine at Texas Tech University Health Sciences Center in Lubbock, TX.

Submitted: $3 / 25 / 2017$

Accepted: 4/9/2017

Reviewers: Christopher Piel MD, Todd Anderson PhD Conflicts of interest: none

\section{REFERENCES}

1. Ober JA. Mineral Commodity Summaries 2017. https://minerals. usgs.gov/minerals/pubs/commodity/nitrogen/mcs-2017-nitro.pdf. Accessed March 20, 2017
2. Orr M F, Sloop S, Wu J. Acute chemical incidents surveillance-Hazardous Substances Emergency Events Surveillance, nine states, 1999-2008. CDC. Hazardous Substances Emergency Events Surveillance, nine states, 2008.

3. Mowry JB, Spyker DA, Brooks DE, McMillan N, Schauben JL. 2014 Annual Report of the American Association of Poison Control Centers' National Poison Data System (NPDS): 32nd Annual Report. Clin Toxicol (Phila) 2015 Dec. 53 (10):962-1147

4. West Fertilizer Explosion and Fire - Investigations $\mid$ the U.S. Chemical Safety Board. http://www.csb.gov/west-fertilizer-explosion-and-fire-/. Accessed March 20, 2017.

5. Levine MD, Zane R. Chemical Injuries. In: Rosen's Emergency Medicine. 8th ed. Philadelphia, PA: Elsevier/Saunders; 2014:818-827.e1.

6. Swotinsky R B, Chase K H. Health effects of exposure to ammonia: Am J Ind Med 1990; 17:515-521.

7. Mulder JS, Van der Zahm HO. Fatal case of ammonium poisoning. Tydschrift Voor Sociale Geneeskunde (Amsterdam) 1967; 45:458-460

8. Newman LS, Bird KG. Chapter 56 - Toxic Inhalational Lung Injury. In: Silvestri GA, Agustí A, eds. Clinical Respiratory Medicine (Fourth Edition). Philadelphia: W.B. Saunders; 2012:682-689.

9. Hoeffler HB, Schweppe HI, Greenberg SD. Bronchiectasis following pulmonary ammonia burn. Arch Pathol Lab Med 1982; 106:686-7.

10. Leonard LG, Scheulen JJ, Munster AM. Chemical burns: effect of prompt first aid. J Trauma 1982; 22:420-3.

11. Amshel CE, Fealk MH, Phillips BJ, et al. Anhydrous ammonia burns: case report and review of the literature. Burns 2000; 26:493-7.

12. Close LG, Catlin FI, Cohn AM. Acute and chronic effects of ammonia burns on the respiratory tract. Arch Otolaryngol 1980; 106:151-8.

13. Leduc D, Gris P, Lheureux P, et al. Acute and long term respiratory damage following inhalation of ammonia. Thorax 1992; 4 7:755-7.

14. White $\mathrm{CE}$, et al. Burn center treatment of patients with severe anhydrous ammonia injury: case reports and literature review. J Burn Care \& Research 2007; 28 (6): 922-928.

15. Arwood R, Hammond J, Ward GG. Ammonia inhalation. J Trauma $1985 ; 25(5): 444-447$.

16. Flury KE, Dines DE, Rodarte JR, Rodgers R. Airway obstruction due to inhalation of ammonia. Mayo Clin Proc 1983 Jun; 58(6):389-93. PubMed PMID: 6855275.

17. Caplin M. ammonia-gas poisoning forty-seven cases in a London shelter. The Lancet 238(6152):95-96.

18. Sobonya R. Fatal anhydrous ammonia inhalation. Hum Pathol 1977; 8:293-9.

19. "National Ag Safety Database - National Ag Safety Database". Nasdonline.org. N.p., 2017. Web. 20 Mar. 2017. 